\title{
Effects of Progesterone Derivatives, Dihydroprogesterone and Tetrahydroprogesterone, on the Subependymal Layer of the Adult Rat
}

\author{
Claudio Giachino, ${ }^{1}$ Mariarita Galbiati, ${ }^{2}$ Aldo Fasolo,, ${ }^{1}$ Paolo Peretto, ${ }^{1}$ \\ Roberto C. Melcangi ${ }^{2}$ \\ ${ }^{1}$ Department of Animal and Human Biology, University of Turin, Via Accademia Albertina 13, 10123 \\ Turin, Italy \\ ${ }^{2}$ Department of Endocrinology and Center of Excellence on Neurodegenerative Diseases, University \\ of Milan, Via Balzaretti 9, 20133 Milan, Italy
}

Received 29 November 2002; accepted 21 July 2003

\begin{abstract}
Indirect evidence suggests that in the subependymal layer (SEL) steroid hormones could be partially involved in the modulation of neurogenesis, but little or nothing is known about a direct effect of these molecules on this cellular system. The possible effect of progesterone (P) and/or its neuroactive metabolites, dihydroprogesterone (DHP) and tetrahydroprogesterone (THP), on the two cellular components of the SEL (i.e., proliferating/migrating neuroblasts and protoplasmic astrocytes) has been analyzed in adult male rat. P, DHP, and THP were administered by intraventricular injections and after 2 days the SEL was analyzed by immunohistochemistry by using anti-glial fibrillary acidic protein (GFAP) and anti-vimentin antibodies, to label the glial compartment, anti-polysialylated form of the neural cell adhesion molecule (PSA-NCAM), anti-Stathmin,
\end{abstract}

and anti- $\beta$ III Tubulin antibodies to label the migrating neuroblasts. Furthermore, the newly formed cells were identified by using intraventricular injections of 5-bromo-2'-deoxyuridine (BrdU) detected immunohistochemically. Our results demonstrate that DHP and THP treatments drastically decrease the number of BrdUlabeled cells within the SEL. THP, DHP, and to a lesser extent $P$, administrations also induce molecular and structural modifications of the SEL glial compartment. On the whole, the present results indicate that neuroactive derivatives of $P$ (i.e., DHP and THP) exert direct effects on adult neurogenesis, strongly affecting both neuroblasts and astrocytes of the SEL. () 2003 Wiley Periodicals, Inc. J Neurobiol 58: 493-502, 2004

Keywords: neuroactive steroids; progesterone metabolites; subependymal layer; cell proliferation; glial tubes

\section{INTRODUCTION}

The genesis of new neurons in the major part of the brain usually corresponds to a well-defined developmental period. However, in specific areas of the adult

Correspondence to: P. Peretto (paolo.peretto@unito.it).

Contract grant sponsor: MURST.

Contract grant sponsor: Compagnia di San Paolo.

Contract grant sponsor: Commission of the European Communities; contract grant number: QLK6-CT-2000-00179.

(C) 2003 Wiley Periodicals, Inc.

DOI 10.1002/neu.10290 mammalian central nervous system, such as the subependymal layer (SEL) of the rostral forebrain and the dentate gyrus of the hippocampus, neurogenesis is protracted virtually throughout life (Altman and Das, 1965; Altman, 1969; Cameron et al., 1993; Luskin, 1993; Lois and Alvarez-Buylla, 1994). Light and electron microscopy studies have demonstrated the existence of two cellular compartments within the SEL: 1) chains of proliferating/migrating neuroblasts expressing the embryonic polysialylated form of the neural cell adhesion molecule (PSA-NCAM) (Bonfanti and Theodosis, 1994; Rousselot et al., 1995); 2) protoplasmic astrocytes that give rise to a channel system (glial 
tubes) that separates the chains of proliferating/migrating cells from the surrounding mature tissue (Jankowski and Sotelo, 1996; Lois et al., 1996; Peretto et al., 1997). SEL astroglia shows peculiar characteristics and may play a crucial role in creating a permissive environment (niche) for adult neurogenesis (Jankowski and Sotelo, 1996; Lim et al., 2000; Coskun et al., 2001; Peretto et al., 2002). Throughout life, the SEL provides a continuous supply of newly formed cells that, after long tangential migration within the SEL rostral extension (SEL-RE), reach the olfactory bulb (OB) and differentiate into interneurons (Luskin, 1993) within the granular and glomerular layers (Lois and Alvarez-Buylla, 1994).

Several studies carried out over the last few years have shown that the proliferation and survival of newly generated granule cells in the adult hippocampus are modulated by diverse environmental (Gould et al., 1999; Van Praag et al., 1999) and hormonal factors (Gould et al., 1992; Cameron and Gould, 1994; Tanapat et al., 1999). In particular, it has been shown that steroid hormones can act on adult hippocampal neurogenesis by modulating cell proliferation (Gould et al., 1992; Cameron and Gould, 1994; Tanapat et al., 1999). Within the SEL it has been demonstrated that estrogens may be responsible, at least in part, for the increased proliferation observed during estrus induction in the prairie vole (Smith et al., 2001). Furthermore, migrating neuroblasts of the SEL rostral migratory stream also reach the rat accessory olfactory bulb (AOB) (Bonfanti et al., 1997). The AOB is a well known sexually dimorphic structure that develops under the control of sexual steroids and shows, during adulthood, a sexually dimorphic distribution of the rostral migratory stream neuroblasts within its anterior part (Peretto et al., 2001). Even if this indirect evidence suggests that steroid hormones could be involved in the modulation of adult neurogenesis in the SEL (Smith et al., 2001), little or nothing is known about a direct effect of these molecules on this cellular system.

The central nervous system contains the enzymes involved in the synthesis of a variety of steroids, forming the so-called neurosteroids (Baulieu, 1998; Compagnone and Mellon, 2000; Melcangi and Panzica, 2001; Mellon et al., 2001). Moreover, the nervous system is able to convert neurosteroids, or hormonal steroids coming from the periphery, in metabolites called neuroactive steroids (Melcangi et al., 1999, 2001a; Melcangi and Panzica, 2001). For instance, progesterone $(\mathrm{P})$, which is also synthesized in the nervous system (Compagnone and Mellon, 2000; Mellon et al., 2001), may be further $5 \alpha$-reduced into dihydroprogesterone (DHP) and subsequently
$3 \alpha$-hydroxylated into tetrahydroprogesterone (THP), respectively via the enzymes $5 \alpha$-reductase $(5 \alpha-\mathrm{R})$ and $3 \alpha$-hydroxysteroid dehydrogenase ( $3 \alpha$-HSD) (Melcangi et al., 1999, 2001a). Interestingly, at least in vitro, $\mathrm{P}$ and its metabolites seem to be able to influence the glial compartment of the SEL (i.e., protoplasmic astrocytes). Utilizing a primary culture of type 1 astrocytes, which probably in vitro correspond to protoplasmic astrocytes present in vivo, we have previously demonstrated that P, DHP, and THP can modulate the gene expression of glial fibrillary acidic protein (GFAP) (Melcangi et al., 1996b). Consequently, in this work we have analyzed whether $\mathrm{P}$ and its metabolites (i.e., DHP and THP) may influence in vivo the two cellular compartments of the SEL in adult rats (i.e., proliferating/migrating neuroblasts and glial tubes). To this purpose, we have injected into the lateral ventricle $\mathrm{P}, \mathrm{DHP}$, or THP and analyzed after 2 days the SEL by immunohistochemistry by using markers for both the glial compartment (GFAP and vimentin) and the migrating neuroblasts (PSANCAM, Stathmin, $\beta$-III Tubulin); (Peretto et al., 1999). Finally, the newly formed proliferating cells were identified and counted at the level of the OB 2 days after intraventricular injections of 5-bromo-2'deoxyuridine (BrdU).

\section{METHODS}

\section{Animals}

The experiments were performed on adult male rats (300$325 \mathrm{~g})$ of Sprague-Dawley strain $\left(\mathrm{Crl}: \mathrm{CD}^{\circledR} \mathrm{BR}\right.$; Charles River, Calco, Italy). Experimental procedures were in accordance with the institutional guidelines for animal welfare. The rats were maintained in rooms with controlled temperature $\left(22 \pm 1{ }^{\circ} \mathrm{C}\right)$ and relative humidity $(60 \%)$, with a lighting schedule of $12 \mathrm{~h}$ of light and $12 \mathrm{~h}$ of darkness (light on 07.00-19.00 h), and with standard diet and water ad libitum. To achieve the intraventricular (i.v.) injections, the rats were implanted with a guide cannula placed into the right lateral cerebral ventricle. The animals were deeply anaesthetized with pentobarbital $(30 \mathrm{mg} / \mathrm{kg}$, i.p.) and correctly positioned on a stereotaxic (Stoelting 51200). The skin of the head was cut, and the theca of the skull exposed. With a dental drill a hole was made, $1 \mathrm{~mm}$ posteriorly and 1 mm laterally to the bregma. A guide cannula (20-gauge), with a metallic support, was lowered into the brain to a depth of 5 $\mathrm{mm}$ and the correct location of the needle was verified through the flow of a minimal amount of cerebrospinal fluid. The cannula was fixed on the skull with dental cement and closed with silicone to avoid loss of cerebrospinal fluid. 


\section{Treatments}

The rats were treated, 2 days after the implantation, with $\mathrm{P}$, DHP, or THP. Steroids, obtained from Sigma Chemicals (Milan, Italy), were dissolved in ethanol (75\% in saline). BrdU (Boehringer, Germany) was dissolved in Tris-HCl 0.1 $M, \mathrm{pH} \mathrm{7.4}$, at the concentration of $10 \mathrm{mg} / \mathrm{mL}$. Rats were injected with steroids $(9 \mu \mathrm{g} / 3.6 \mu \mathrm{L})$ and with $\operatorname{BrdU}(3 \mu \mathrm{L})$ directly into the lateral ventricle. The control group was treated with i.v. injections of $\operatorname{BrdU}(3 \mu \mathrm{L})$ and ethanol (3.6 $\mu \mathrm{L}-75 \%$ in saline). Forty-eight hours after the i.v. treatments, the rats were deeply anaesthetized with intraperitoneal ketamine (700 $\mu \mathrm{L}$; Ketavet; Gellini, Italy) and xylazine (200 $\mu \mathrm{L}$; Rompun; Bayer, Germany) and then intracardially perfused with $4 \%$ paraformaldehyde in $0.1 \mathrm{M}$ phosphate buffer, $\mathrm{pH}$ 7.4. The brains were postfixed for $12 \mathrm{~h}$ in the same solution, cryoprotected in ascending sucrose solutions, frozen, and cryostat-sectioned. The brains were serially sectioned in the coronal plane and free-floating sections (25 $\mu \mathrm{m})$ were collected in multiwell dishes. Series of sections representing the SEL were stored at $-20^{\circ} \mathrm{C}$ in antifreeze solution until use.

\section{Immunohistochemistry}

For BrdU immunostaining free floating sections were treated with $2 \mathrm{M} \mathrm{HCl}$ for $1 \mathrm{~h}$ at $37^{\circ} \mathrm{C}$ and then neutralized with borate buffer, $\mathrm{pH}$ 8.5. Sections were incubated for $24 \mathrm{~h}$ at $4{ }^{\circ} \mathrm{C}$ in primary antibody diluted in $0.01 \mathrm{M}$ PBS, $\mathrm{pH} 7.4$, $0.5 \%$ Triton X-100, $1 \%$ normal serum. For GFAP immunohistochemistry sections were incubated for $48 \mathrm{~h}$ at $4{ }^{\circ} \mathrm{C}$ in primary antibody diluted in $0.01 M \mathrm{PBS}, \mathrm{pH} 7.4,1 \%$ Triton $\mathrm{X}-100$. The primary antibody dilutions were $1: 150$ for aBrdU (monoclonal mouse IgG; Boehringer), 1:120 for aGFAP (monoclonal mouse IgG; Boehringer), and 1:2500 for a-PSA-NCAM (monoclonal mouse IgM; a generous gift of G. Rougon, University of Aix-Marseille, France). Sections were incubated for $1 \mathrm{~h}$ at room temperature in secondary biotinylated antibody (a-mouse IgG; Vector; amouse IgM; Sigma-Aldrich, Italy) diluted 1:200 in 0.01 M PBS, $\mathrm{pH} 7.4,0.5 \%$ Triton $\mathrm{X}-100$ followed by the avidinbiotin-peroxidase complex (Vector). To reveal immunoreactivity we used $0.015 \%$ 3,3'-diaminobenzidine, $0.0024 \%$ $\mathrm{H}_{2} \mathrm{O}_{2}$ in $0.05 M$ Tris-HCl, pH 7.6. After adhesion on slides, sections were dehydrated and mounted in Sintex (Nuova Chimica, Italy).

\section{Immunofluorescence}

For immunofluorescent double labeling of BrdU and class III $\beta$-Tubulin, BrdU and Stathmin, or BrdU and GFAP we used monoclonal rat a-BrdU (1:1000; Harlan), rabbit a- $\beta$ Tubulin (1:600; BABCO), rabbit a-Stathmin (1:800; a generous gift of A. Sobel, University of Paris, France), and monoclonal mouse a-GFAP (1:120 IgG; Boehringer). Sections were incubated for $48 \mathrm{~h}$ at $4^{\circ} \mathrm{C}$ in a- $\beta$-III Tubulin, a-Stathmin, or a-GFAP primary antibody and appropriate serum and then were incubated for $1 \mathrm{~h}$ at room temperature in secondary antibody (Cy3 a-mouse IgG+IgM; Jackson ImmunoResearch; Cy3 a-rabbit; Sigma) diluted 1:800. Sections were treated with $2 \mathrm{M} \mathrm{HCl}$ for $30 \mathrm{~min}$ at $37^{\circ} \mathrm{C}$, neutralized with borate buffer $\mathrm{pH} 8.5$, and incubated for $24 \mathrm{~h}$ at $4^{\circ} \mathrm{C}$ in primary a-BrdU antibody and appropriate serum. Then sections were incubated for $1 \mathrm{~h}$ at room temperature in secondary biotinylated antibody (a-rat IgG mouse-adsorbed; Vector) diluted 1:200 followed by avidinFITC (Vector). Sections were mounted, air-dried, and coverslipped in polyvinyl alcohol with diazabicyclo-octane (DABCO) as an antifading agent. Fluorescent signals were detected using a FV 200 Olympus Fluoview confocal laserscanning microscope. The phenotype of BrdU-labeled cells within the SEL was analyzed in control and treated rats.

\section{Counts of BrdU Immunoreactive Cells}

A total number of 16 male rats were used $(n=4$ for each treatment). To evaluate the rate of cell proliferation in different experimental groups, one series of coronal sections, from the injected hemisphere, was immunohistochemically labeled for BrdU. BrdU-labeled nuclei were counted in coronal sections of the anterior SEL cut at the AOB level (Bregma level between 5.6 and $6.6 \mathrm{~mm}$; Paxinos and Watson, 1982). For each animal three coronal sections were analyzed by means of an image-analysis workstation based on an Olympus microscope, a camera (CoolSNAPPro color RS Photometrics; Media Cybernetics), and the image-analysis software Image Pro-Plus 4.1 for Windows (Copyright 1994, 1999 Media Cybernetics L.P.). The area of the SEL (defined as the region between the anterior olfactory nucleus, the granular layer of the main $\mathrm{OB}$ and the $\mathrm{AOB})$ was measured and the number of BrdU-positive nuclei within the selected region was determined. The number of BrdU labeled nuclei was estimated by using a cell splitting correction factor based on the Abercrombie method (Abercrombie, 1946) and the formula $\mathrm{P}=A(M / L+M)$, where $A$ is the number of labeled nuclei per unit area, $M$ is the section thickness, and $L$ is the average diameter of $\mathrm{BrdU}$ labeled nuclei. Cell diameters from 200 cells per group were measured. No difference in cell diameter was found between groups. Collected data were used to estimate the number of BrdU positive nuclei per $\mathrm{mm}^{3}$. Data were analyzed for one-way ANOVA followed by Newman-Keuls $t$ test (NK $t$ test).

\section{RESULTS}

\section{Cell Proliferation and PSA-NCAM Immunoreactivity}

In control animals, 2 days after a single injection of BrdU into the lateral ventricle, numerous BrdU-immunoreactive nuclei were visible through the anteriorposterior extent of the SEL, from the SEL of the lateral ventricle (SEL-LV) to the SEL of the olfactory 


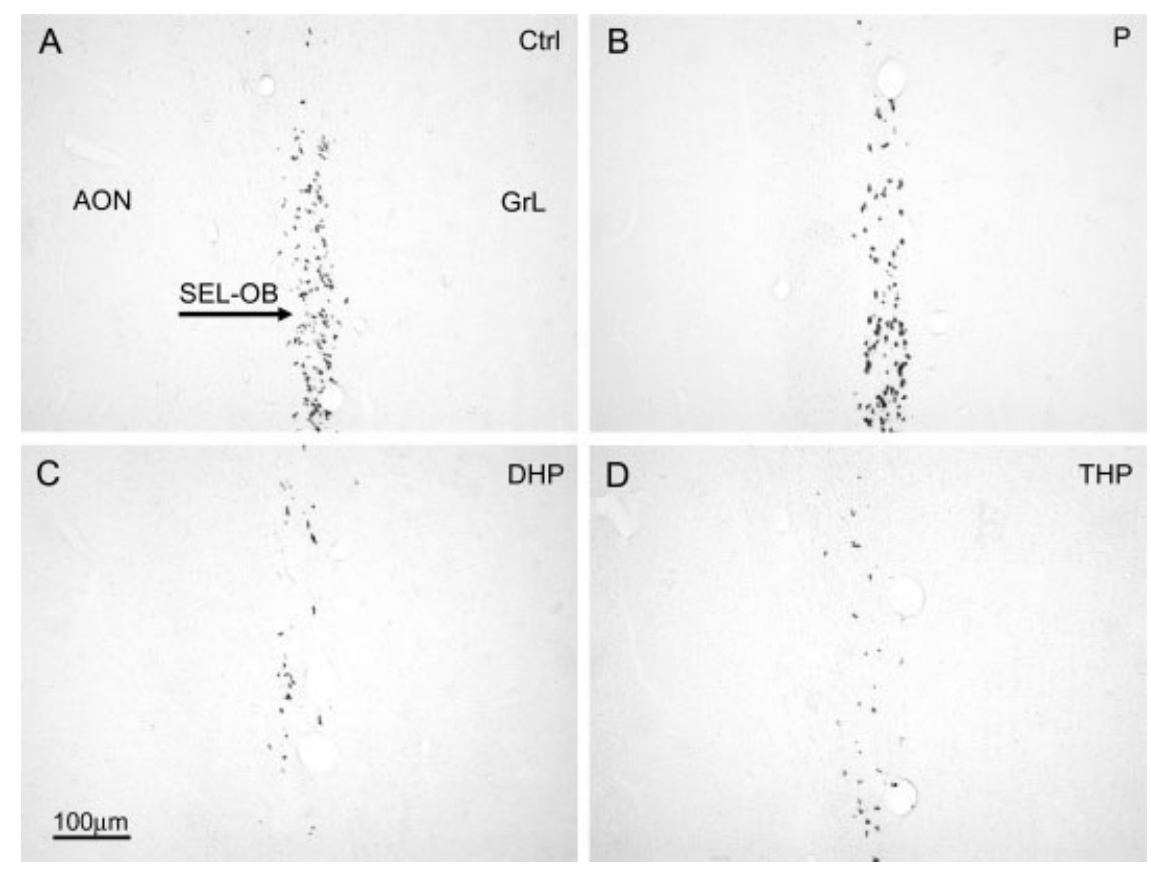

Figure 1 BrdU immunostaining in coronal sections cut at the same level of the SEL-OB of control (A) and treated (B,C,D) rats. At 2 days from the treatment, DHP- and THP-injected rats show evident reduction of BrdU-immunostaining. Ctrl, control; P, progesterone; DHP, dihydroprogesterone; THP, tetrahydroprogesterone; SEL-OB, subependymal layer of the olfactory bulb; AON, anterior olfactory nucleus; GrL, granular layer of the main olfactory bulb.

bulb (SEL-OB). In thick $(25 \mu \mathrm{m})$ coronal sections cut at the level of the SEL-LV and SEL-RE, the labeled nuclei were densely packaged and frequently overlapped. In more anterior sections (SEL-OB) BrdUpositive nuclei were numerous but more dispersed. Only few BrdU-immunoreactive nuclei were visible through the OB layers, indicating that at 2 days postinjection virtually all the labeled proliferating/ migrating cells were still located within the SEL and had not reached the OB granular and glomerular layers (Fig. 1). All treatments (P, DHP, THP) apparently reduced BrdU immunostaining within the SEL-LV in the proximity of the injection site (not shown) and less robustly in more anterior regions. However, only DHP and THP induced a visible reduction of BrdU immunostaining within the whole extent of the SEL (Fig. 1).

To evaluate the supply of newly generated cells in the OB, BrdU-labeled nuclei were counted in coronal sections of the anterior SEL from the injected hemisphere of control and treated (P, DHP, and THP) rats. Data analyzed for one-way ANOVA demonstrated a significant difference between the groups. The analysis between control and P-treated rats did not show any significant difference. Conversely, the number of BrdU-positive nuclei was significantly decreased in
THP and DHP versus control and P-treated rats (NK $t$ test, $p<0.05$, Figs. 1 and 2).

To analyze whether steroid treatment can modify the phenotypic differentiation of the newly generated (BrdU-positive) cells, we performed double labeling for BrdU and neuronal ( $\beta-$ III Tubulin) or glial (GFAP) markers or for BrdU and Stathmin, a marker

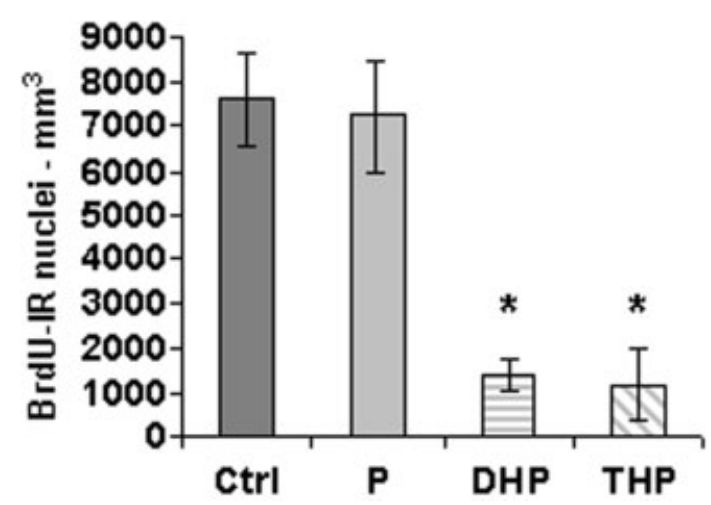

Figure 2 Mean numbers of BrdU-labeled nuclei per $\mathrm{mm}^{3}$ within the SEL-OB. DHP and THP treatments strongly reduce the number of labeled nuclei in the SEL. Data are mean \pm standard error. $* p<0.05$ compared to control and $\mathrm{P}$ treated rats. Ctrl, control; $\mathrm{P}$, progesterone; DHP, dihydroprogesterone; THP, tetrahydroprogesterone. 


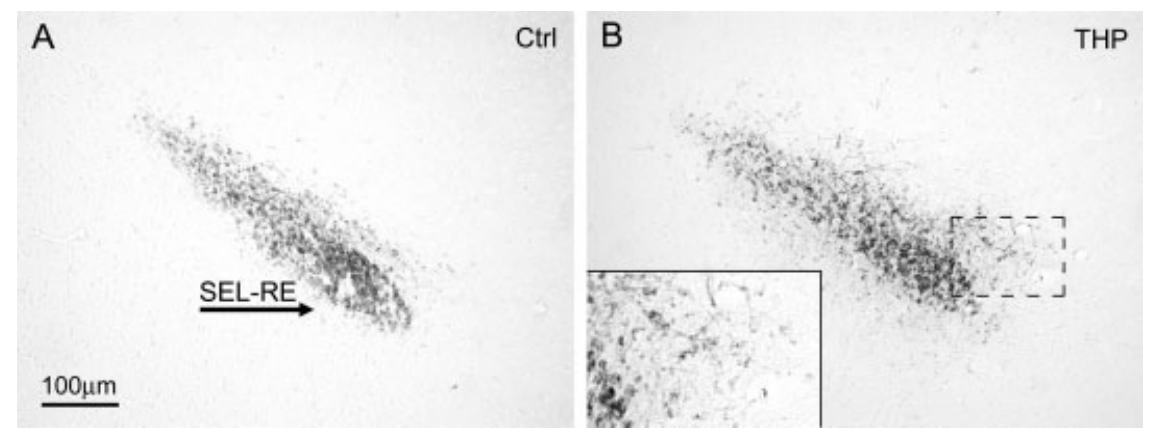

Figure 3 PSA-NCAM immunostaining in coronal sections of the SEL-RE. Chains of migrating cells are visible within the SEL both in control (A) and in THP-treated (B) rats. Some isolated cells are visible outside the SEL-RE of THP-treated rats [insert in (B)]. SEL-RE, subependymal layer rostral extension.

of SEL migrating neuroblasts (Camoletto et al., 1997). Our results showed that virtually all the BrdUlabeled cells within the SEL express $\beta$-III Tubulin and Stathmin, revealing their neuronal nature, both in control and treated rats (data not shown).

Treatments did not modify the immunoreactivity for PSA-NCAM, a molecule associated in the SEL with proliferating/migrating cells (Bonfanti and Theodosis, 1994; Rousselot et al., 1995). In all experimental groups chains of migrating cells strongly immunoreactive for the PSA-NCAM were visible within the SEL-RE (Fig. 3). Nevertheless, in THP-treated rats, some bipolar PSA-NCAM positive cells were detected at a short distance outside the SEL-LV and SEL-RE [Fig. 3(B)].

\section{SEL Astrocytes}

The SEL glial compartment was studied in serial coronal sections, representative of the whole system, treated with antibodies directed against the astroglial specific marker GFAP and vimentine, an intermediate filament protein abundantly expressed by immature glial cells, such as the radial glia (Pixley and de Vellis, 1984), and retained by astrocytes of the glial tubes (Peretto et al., 1997, 1999). This analysis showed that THP and, to a lesser extent, DHP treatments lead to a reduction of GFAP immunoreactivity within the SEL region, and modifications of the typical structural organization of the glial tubes. Changes induced by THP and DHP appear particularly evident at the level of the SEL-LV (not shown) and SEL-RE (Figs. 4 and 5). After intraventricular injection of $\mathrm{P}$ only few modifications were found mostly restricted to the injection site. THP also reduced GFAP immunoreactivity in the parenchyma lining the SEL border (Figs. 4 and 5). However, moving radially away from the SEL, DHP, THP, and P did not modify GFAPimmunoreactivity, suggesting that treatments principally affect the glial tubes (Figs. 4 and 5). Frequently, in the THP-treated animals, the SEL-RE contralateral to the injection site showed similar but weaker modifications (Fig. 5). By contrast, all the treatments apparently never modified the glial compartment within the SEL-OB.

Anti-vimentin analysis, performed in parallel sections, demonstrated the presence of vimentin-positive astrocytic processes along the SEL extent, suggesting a down-regulation of GFAP protein in this region and not a disappearance of astrocytic glial cells (not shown). Nevertheless, a partial structural disorganization of the glial tubes, namely a reduction of density of astrocytic processes, was found in THP- and DHPtreated animals (Figs. 4 and 5). These changes of the glial compartment, particularly evident at the level of the SEL-RE, are matched with an enlargement of the SEL as shown by coronal sections stained with antiGFAP and anti-PSA-NCAM antibodies (Figs. 3-5) or counterstained with cresyl violet (not shown).

\section{DISCUSSION}

In this study we have demonstrated, for the first time, that the P-derived neuroactive steroids, DHP and THP can modulate adult SEL neurogenesis. In particular, injections of THP and DHP into the lateral ventricle of the adult rat strongly reduced the number of proliferating cells within the SEL and modified some molecular and structural characteristics of the glial tubes, thus affecting both the actively proliferating and glial compartments of the SEL.

Our quantitative analysis demonstrated that the number of BrdU labeled nuclei in the anterior SEL 

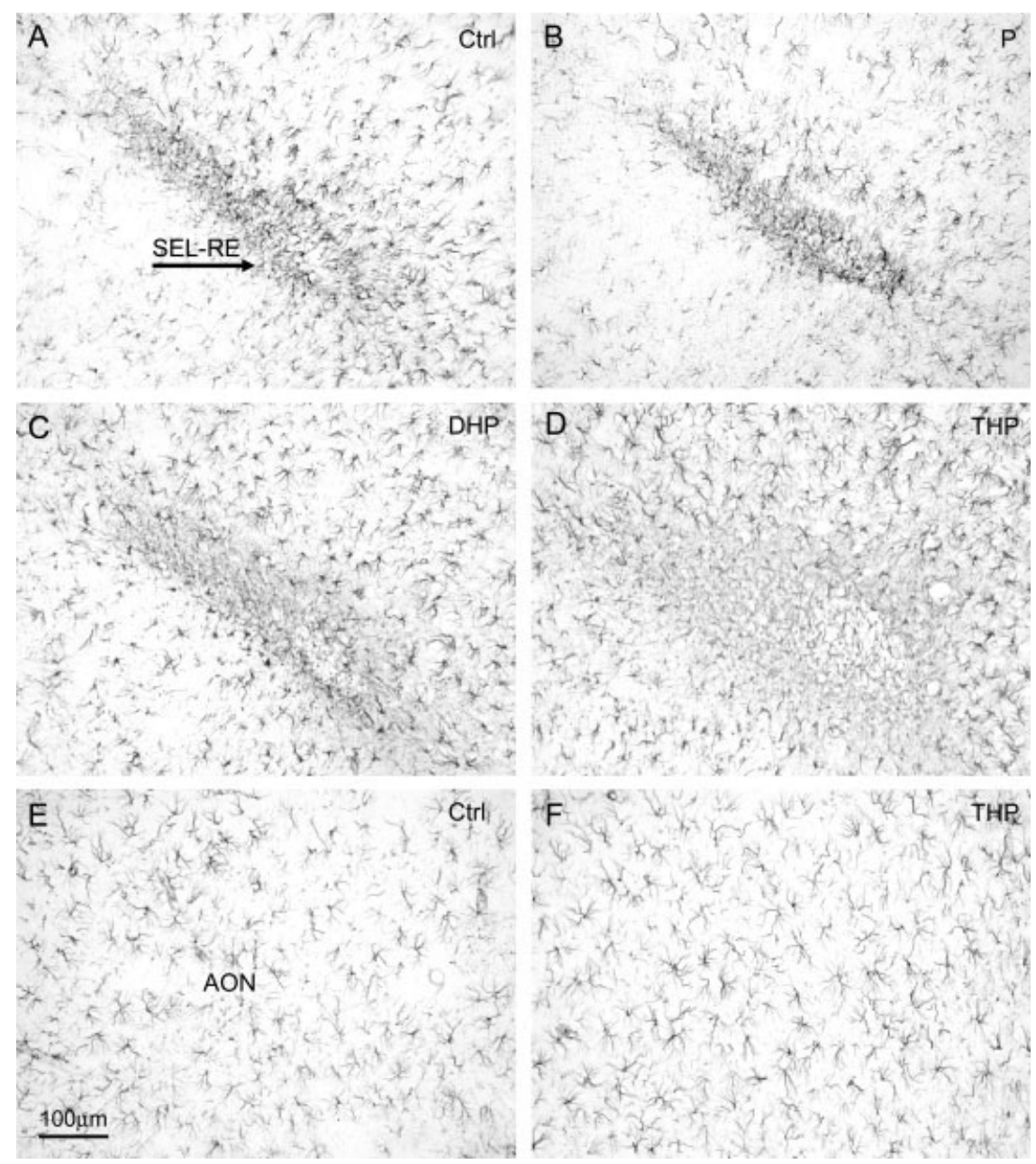

Figure 4 GFAP immunostaining in coronal sections cut at the same level of the SEL-RE of control (A) and treated $(B, C, D)$ rats. Note the structural disorganization of the glial tubes and the reduction of GFAP immunoreactivity in THP- and DHP-treated rats. (E,F) Immunoreactivity for GFAP in the AON of control (E) and THP-treated (F) rats confirmed that treatments principally affect the SEL astrocytic glial compartment. Images (E) and (F) are from the same sections of images (A) and (D). Ctrl, control; P, progesterone; DHP, dihydroprogesterone; THP, tetrahydroprogesterone; SEL-RE, subependymal layer rostral extension; AON, anterior olfactory nucleus.

(i.e., at the level of the $\mathrm{AOB}$ ) is several-fold decreased in THP- and DHP-treated animals in comparison to control and P-treated animals (Fig. 2). Such reduction of BrdU-positive nuclei in the SEL-OB can be explained by the following main reasons: (i) decreased cell division; (ii) reduced migration of neuroblasts from the posterior SEL towards the OB; (iii) reduced cell survival of proliferating labeled cells. Previous studies have demonstrated that some classes of steroid hormones (glucocorticoids and estrogens) can act on adult hippocampal neurogenesis by modulating cell proliferation (Gould et al., 1992; Cameron and Gould, 1994; Tanapat et al., 1999). Interestingly, a recent study supplied indications for a potential regulative role of estrogens on adult SEL proliferation (Smith et al., 2001). These overall studies, and the reduction of BrdU-positive nuclei found in our research after THP and DHP treatments, suggest that different classes of steroid hormones (glucocorticoids, estrogens, and now the $p$ derivatives) can modulate adult neurogenesis, in the hippocampus and the SEL, by regulating the proliferative activity of progenitor cells. As far as a possible interference of DHP and THP with migratory mechanisms of the SEL neuroblasts (see above point ii) is concerned, it is important to consider that, whereas it has been demonstrated that neuroblasts continue to proliferate along their migratory pathway (Menezes et al., 1995) and neural stem cells are present until the SEL-OB (Gritti et al., 2002), the largest number of neuroblasts migrating to the $\mathrm{OB}$ 


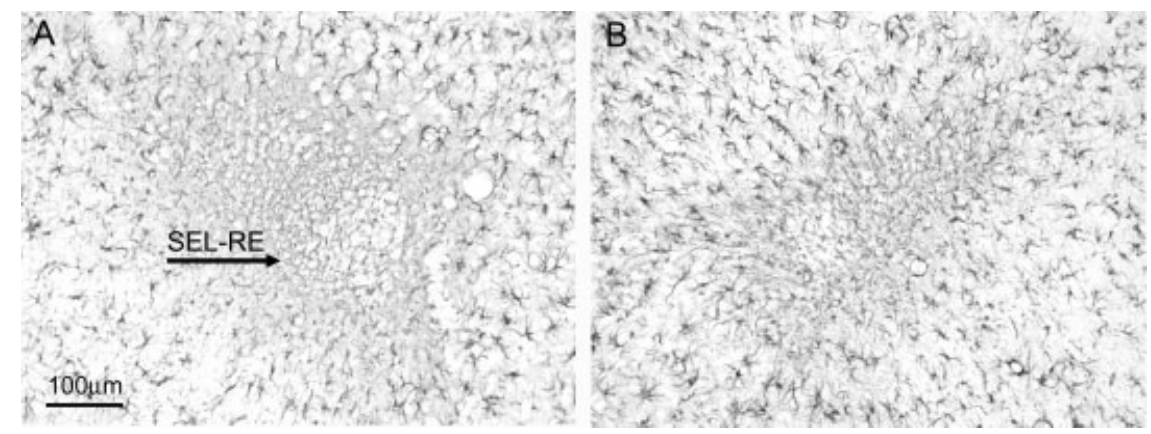

Figure 5 GFAP immunostaining in coronal sections of the SEL-RE of THP-treated rats. Glial tubes are disorganized and GFAP immunoreactivity is reduced within the SEL mainly in the injected hemisphere (A), but also in the contralateral hemisphere (B). The level is more posterior than in Figure 4 . SEL-RE, subependymal layer rostral extension.

originate in the SEL-LV, which represents the principal source of the SEL newly formed cells. Our qualitative analysis, performed along the SEL extent, showed lack of clustered proliferating labeled cells within the caudal SEL and that THP or DHP treatment strongly reduced $\mathrm{BrdU}$ immunolabeling along the whole system. These results, together with the presence of "normal" PSA-NCAM immunopositive chains in treated animals, prompt us to exclude defects of the migratory mechanism. Altogether these data suggest that THP and DHP affect principally cell proliferation, rather than cell migration. Finally, we cannot exclude that the reduction of BrdU-positive nuclei, due to the THP and DHP treatments, could be related to an increase in cell death, because apoptotic cell death normally occurs along the SEL rostral migratory stream (Brunjes and Armstrong, 1996). By contrast to $\mathrm{P}$ metabolites, cell proliferation in the anterior SEL is not changed in the P-treated animals. This result is in agreement with recent studies showing no clear modification of BrdU immunostaining in the SEL after subcutaneous or intraventricular injections of P (Alonso, 2000; Shingo et al., 2003). This different behavior on SEL proliferation can be explained considering the distribution and types of receptors of P, DHP, and THP, and the enzymatic complex regulating their reciprocal interconversion. The problem of receptors involved in THP and DHP action on the SEL remains to be clarified. So far no evidence in literature demonstrates a direct action of $\mathrm{P}$ and its neuractive derivatives on neuroblast proliferation. Moreover, it is unknown whether these cells express the $\mathrm{P}$ receptor (PR). On the other hand, it is important to highlight that while DHP, like $\mathrm{P}$ itself, is able to bind to the PR, THP represents a potent ligand of the $\mathrm{GABA}_{\mathrm{A}}$ receptor (Melcangi et al., 1999, 2001a). A potential involvement of the $\mathrm{GABA}_{\mathrm{A}}$ receptor in our system is suggested by some develop- mental studies. Neuronal progenitors of the postnatal rat subventricular zone (SVZ), namely the SEL precursor region, express functional $\mathrm{GABA}_{\mathrm{A}}$ receptors (Stewart et al., 2002) and GABA decreases cell proliferation in the embryonic SVZ (Haydar et al., 2000). These data support the hypothesis that THP may act directly on neuroblast proliferation by activation of the $\mathrm{GABA}_{\mathrm{A}}$ receptor. Considering THP as being responsible for the effect on neuroblast proliferation, the effect exerted by DHP might be ascribed to its conversion into THP by the action of the $3 \alpha$-HSD enzyme. This hypothesis might be strengthened by our previous observations indicating that considerable levels of enzymatic activities converting steroid hormones into neuroactive steroids are also present in undifferentiated cells, such as stem cells originating from the mouse striatum (Melcangi et al., 1996a). Thus, the lack of effect on proliferation following $P$ injection could be due to the absence of PR in the actively proliferating cells, or to the time course necessary for the conversion of P into DHP and subsequently into THP. Previous studies have demonstrated that, in normal conditions, the newly formed cells of the SEL express class III $\beta$-Tubulin, a marker for young neurons (Doetsch and Alvarez-Buylla, 1996; Jankovski and Sotelo, 1996; Peretto et al., 1997), and differentiate into $\mathrm{OB}$ local interneurons (Luskin, 1993; Lois and Alvarez-Buylla, 1994). However, in vitro experiments have demonstrated that the SEL contains multipotent neural stem cells able to give rise to both neurons and glia (Morshead et al., 1994; Gritti et al., 2002). Moreover, i.v. injections of epidermal growth factor can induce glial differentiation of SEL progenitors in vivo (Craig et al., 1996; Kuhn et al., 1997). Thus, to ascertain whether $p$ derivatives can induce a shift in phenotypic differentiation of the proliferating cells, we examined the expression of neuronal and glial markers by newly generated cells. 
Our results indicate that virtually all the BrdU-labeled cells, within the SEL, colocalize with class III $\beta$-Tubulin and the SEL neuroblasts marker Stathmin both in control and treated rats, indicating that THP and DHP do not affect the fate of newborn cells.

Recently, it has been demonstrated that cortical lesions and strokes affect adult neurogenesis by inducing cell proliferation within the SEL and/or migration of newly generated cells into the damaged area (Magavi et al., 2000; Jin et al., 2001; Arvidsson et al., 2002). These data suggest that i.v. injections, widely used to study the behavior of the SEL proliferating neuroblasts (Lois and Alvarez-Buylla, 1994; Craig et al., 1996; Kuhn et al., 1997), might modify neurogenesis in the SEL region. Nevertheless, the reduction of BrdU-positive nuclei, observed in the SEL-OB of THP- and DHP-treated rats, must be principally determined by steroid treatments because both control and treated animals were injected in the lateral ventricle and we analyzed the SEL-RE and SEL-OB several millimeters far from the injection site.

It is important to note that our data also indicate that neuroactive derivatives of $\mathrm{P}$ influence the SEL glial compartment. THP, DHP, and P, although with different intensity, act on glial tubes, modifying their organization and decreasing GFAP-immunoreactivity in SEL astrocytes. Structural changes of the glial tubes can explain the presence, outside the SEL-RE of THP-treated rats (see Fig. 3), of PSA-NCAM-immunoreactive cells that may represent ectopic migrating neuroblasts. An effect of neuroactive steroids on glial cells is not surprising because they express both classical (i.e., PR) and nonclassical (i.e., $\mathrm{GABA}_{\mathrm{A}}$ ) steroid receptors and consequently this cellular compartment is now considered a target for these molecules (Melcangi et al., 2001b). In this context, it is important to remember that, in agreement with the present in vivo observations, we have observed that DHP and THP down-regulate GFAP gene expression in culture of protoplasmic astrocytes (Melcangi et al., 1996b). Consequently, because astrocytes express both PR and $\mathrm{GABA}_{\mathrm{A}}$ receptor (Melcangi et al., 2001b), the effects exerted by HP and THP in vivo might be ascribed to interaction with $\mathrm{PR}$, or with $\mathrm{GABA}_{\mathrm{A}}$ receptor, or to a mixed action. To this purpose, future experiments will be required to explain the receptors involved in such effects.

Finally, considering the putative importance of the glial cells in this cellular system, it is also possible to hypothesize that the effects exerted by neuroactive steroids on neuroblast proliferation might also be a consequence of impaired function of the glial compartment (e.g., reduced release of neurogenetic factors). Indeed, many different studies are now focusing on the importance of astrocytic glial cells of this system that show very particular molecular characteristics and can actually provide the stem cell niche and stem cell reservoir of the SEL (Doetsch et al., 1999; Lim et al., 2000; Peretto et al., 2002).

This work was supported by the Commission of the European Communities, specific RTD program "Quality of Life and Management of Living Resources," QLK6-CT2000-00179. We thank Mrs. P. Assi for providing excellent technical assistance.

\section{REFERENCES}

Abercrombie M. 1946. Estimation of nuclear population from microtome sections. Anat Rec 94:239-247.

Alonso G. 2000. Prolonged corticosterone treatment of adult rats inhibits the proliferation of oligodendrocyte progenitors present throughout white and gray matter regions of the brain. Glia 31:219-231.

Altman J. 1969. Autoradiographic and histological studies of postnatal neurogenesis. IV. Cell proliferation and migration in the anterior forebrain, with special reference to persisting neurogenesis in the olfactory bulb. J Comp Neurol 137:433-457.

Altman J, Das GD. 1965. Autoradiographic and histological evidence of postnatal hippocampal neurogenesis in rats. J Comp Neurol 124:319-335.

Arvidsson A, Collin T, Kirik D, Kokaia Z, Lindvall O. 2002. Neuronal replacement from endogenous precursors in the adult brain after stroke. Nat Med 8:963-970.

Baulieu EE. 1998. Neurosteroids: a novel function of the brain. Psychoneuroendocrinology 23:963-987.

Bonfanti L, Peretto P, Merighi A, Fasolo A. 1997. Newlygenerated cells from the rostral migratory stream in the accessory olfactory bulb of the adult rat. Neuroscience 81:489-502.

Bonfanti L, Theodosis DT. 1994. Expression of polysialylated neural cell adhesion molecule by proliferating cells in the subependymal layer of the adult rat, in its rostral extension and in the olfactory bulb. Neuroscience 62: 291-305.

Brunjes PC, Armstrong AM. 1996. Apoptosis in the rostral migratory stream of the developing rat. Brain Res Dev Brain Res 92:219-222

Cameron HA, Gould E. 1994 Adult neurogenesis is regulated by adrenal steroids in the dentate gyrus. Neuroscience 61:203-209.

Cameron HA, Woolley CS, McEwen BS, Gould E. 1993. Differentiation of newly born neurons and glia in the dentate gyrus of the adult rat. Neuroscience 56:337-344.

Camoletto P, Peretto P, Bonfanti L, Manceau V, Sobel A, Fasolo A. 1997. The cytosolic phosphoprotein stathmin is expressed in the olfactory system of the adult rat. NeuroReport 8:2825-2829.

Compagnone NA, Mellon SH. 2000. Neurosteroids: biosyn- 
thesis and function of these novel neuromodulators. Front Neuroendocrinol 21:1-56.

Coskun V, Venkatraman G, Yang H, Rao MS, Luskin MB. 2001. Retroviral manipulation of the expression of bone morphogenetic protein receptor Ia by SVZa progenitor cells leads to changes in their p19(INK4d) expression but not in their neuronal commitment. Int $\mathrm{J}$ Dev Neurosci 19:219-227.

Craig CG, Tropepe V, Morshead CM, Reynolds BA, Weiss S, van der Kooy D. 1996. In vivo growth factor expansion of endogenous subependymal neural precursor cell populations in the adult mouse brain. J Neurosci 16:26492658.

Doetsch F, Alvarez-Buylla A. 1996. Network of tangential pathways for neuronal migration in adult mammalian brain. PNAS 93:14895-14900.

Doetsch F, Caille I, Lim DA, Garcia-Verdugo JM, AlvarezBuylla A. 1999. Subventricular zone astrocytes are neural stem cells in the adult mammalian brain. Cell 97:703716.

Gould E, Beylin A, Tanapat P, Reeves A, Shors TJ. 1999. Learning enhances adult neurogenesis in the hippocampal formation. Nat Neurosci 2:260-265.

Gould E, Cameron HA, Daniels DC, Woolley CS, McEwen BS. 1992. Adrenal hormones suppress cell division in the adult rat dentate gyrus. J Neurosci 12:3642-3650.

Gritti A, Bonfanti L, Doetsch F, Caille I, Alvarez-Buylla A, Lim DA, Galli R, Verdugo JM, Herrera DG, Vescovi AL. 2002. Multipotent neural stem cells reside into the rostral extension and olfactory bulb of adult rodents. J Neurosci 22:437-445.

Haydar TF, Wang F, Schwartz ML, Rakic P. 2000. Differential modulation of proliferation in the neocortical ventricular and subventricular zones. J Neurosci 20:57645774.

Jankovski A, Sotelo C. 1996. Subventricular zone-olfactory bulb migratory pathway in the adult mouse: cellular composition and specificity as determined by heterochronic and heterotopic transplantation. J Comp Neurol 371:376396

Jin K, Minami M, Lan JQ, Mao XO, Batteur S, Simon RP, Greenberg DA. 2001. Neurogenesis in dentate subgranular zone and rostral subventricular zone after focal cerebral ischemia in the rat. PNAS 98:4710-4715.

Kuhn HG, Winkler J, Kempermann G, Thal LJ, Gage FH. 1997. Epidermal growth factor and fibroblast growth factor- 2 have different effects on neural progenitors in the adult rat brain. J Neurosci 17:5820-5829.

Lim DA, Tramontin AD, Trevejo JM, Herrera DG, GarciaVerdugo JM, Alvarez-Buylla A. 2000. Noggin antagonizes BMP signaling to create a niche for adult neurogenesis. Neuron 28:713-726.

Lois C, Alvarez-Buylla A. 1994. Long-distance neuronal migration in the adult mammalian brain. Science 264 : 1145-1148.

Lois C, Garcia-Verdugo JM, Alvarez-Buylla A. 1996. Chain migration of neuronal precursors. Science 271: 978-981.
Luskin MB. 1993. Restricted proliferation and migration of postnatally generated neurons derived from the forebrain subventricular zone. Neuron 11:173-189.

Magavi SS, Leavitt BR, Macklis JD. 2000. Induction of neurogenesis in the neocortex of adult mice. Nature 405: 951-955.

Melcangi RC, Froelichsthal P, Martini L, Vescovi AL. 1996a. Steroid metabolizing enzymes in pluripotential progenitor CNS cells: effect of differentiation and maturation. Neuroscience 72:467-475.

Melcangi RC, Magnaghi V, Galbiati M, Martini L. 2001a. Formation and effects of neuroactive steroids in the central and peripheral nervous system. Int Rev Neurobiol 46:145-176.

Melcangi RC, Magnaghi V, Galbiati M, Martini L. 2001b. Glial cells: a target for steroid hormones. Prog Brain Res 132:31-40.

Melcangi RC, Magnaghi V, Martini L. 1999. Steroid metabolism and effects in central and peripheral glial cells. J Neurobiol 40:471-483.

Melcangi RC, Panzica GC. 2001. Steroids in the nervous system: a Pandora box? Trends Neurosci 24:311-312.

Melcangi RC, Riva MA, Fumagalli F, Magnaghi V, Racagni G, Martini L. 1996b. Effect of progesterone, testosterone and their 5 alpha-reduced metabolites on GFAP gene expression in type 1 astrocytes. Brain Res 711:10-15.

Mellon SH, Griffin LD, Compagnone NA. 2001. Biosynthesis and action of neurosteroids. Brain Res Rev 37:3-12.

Menezes JR, Smith CM, Nelson KC, Luskin MB. 1995. The division of neuronal progenitor cells during migration in the neonatal mammalian forebrain. Mol Cell Neurosci 6:496-508.

Morshead CM, Reynolds BA, Craig CG, McBurney MW, Staines WA, Morassutti D, Weiss S, van der Kooy D. 1994. Neural stem cells in the adult mammalian forebrain: a relatively quiescent subpopulation of subependymal cells. Neuron 13:1071-1082

Paxinos G, Watson C. 1982. The rat brain in stereotaxic coordinates. Sydney: Academic Press.

Peretto P, Cummings D, Modena C, Behrens M, Venkatraman G, Fasolo A, Margolis FL. 2002. BMP mRNA and protein expression in the developing mouse olfactory system. J Comp Neurol 451:267-278.

Peretto P, Giachino C, Panzica GC, Fasolo A. 2001. Sexually dimorphic neurogenesis is topographically matched with the anterior accessory olfactory bulb of the adult rat. Cell Tissue Res 306:385-389.

Peretto P, Merighi A, Fasolo A, Bonfanti L. 1997. Glial tubes in the rostral migratory stream of the adult rat. Brain Res Bull 42:9-21.

Peretto P, Merighi A, Fasolo A, Bonfanti L. 1999. The subependymal layer in rodents: a site of structural plasticity and cell migration in the adult mammalian brain. Brain Res Bull 49:221-243.

Pixley SK, de Vellis J. 1984. Transition between immature radial glia and mature astrocytes studied with a monoclonal antibody to vimentin. Brain Res 317:201-209.

Rousselot P, Lois C, Alvarez-Buylla A. 1995. Embryonic 
(PSA) N-CAM reveals chains of migrating neuroblasts between the lateral ventricle and the olfactory bulb of adult mice. J Comp Neurol 351:51-61.

Shingo T, Gregg C, Enwere E, Fujikawa H, Hassam R, Geary C, Cross JC, Weiss S. 2003. Pregnancy-stimulated neurogenesis in the adult female forebrain mediated by prolactin. Science 299:117-120.

Smith MT, Pencea V, Wang Z, Luskin MB, Insel TR. 2001. Increased number of BrdU-labeled neurons in the rostral migratory stream of the estrous prairie vole. Horm Behav 39:11-21.
Stewart RR, Hoge GJ, Zigova T, Luskin MB. 2002. Neural progenitor cells of the neonatal rat anterior subventricular zone express functional GABA(A) receptors. J Neurobiol 50:305-322.

Tanapat P, Hastings NB, Reeves AJ, Gould E. 1999. Estrogen stimulates a transient increase in the number of new neurons in the dentate gyrus of the adult female rat. J Neurosci 19:5792-5801.

van Praag H, Kempermann G, Gage FH. 1999. Running increases cell proliferation and neurogenesis in the adult mouse dentate gyrus. Nat Neurosci 2:266-270. 